\title{
Intestinal polyparasitism with special emphasis to soil-transmitted helminths among residents around Gilgel Gibe Dam, Southwest Ethiopia: a community based survey
}

Zeleke Mekonnen $^{1 *}$, Sultan Suleman², Abdissa Biruksew ${ }^{1}$, Tamirat Tefera ${ }^{1}$ and Legese Chelkeba²

\begin{abstract}
Background: One third of the world population is estimated to be infected with intestinal parasites. The most affected people are children and the poor people living in tropics and subtropics. Polyparasitism (the concurrent infection with multiple intestinal parasite species) is found to be the norm among the same population although accurate estimate of its magnitude is unknown. It was found that polyparasitism might have a greater impact on morbidity than single species infection which might also increase susceptibility to other infections. Therefore, this study aimed at determining the prevalence and distribution of intestinal polyparasitism with special emphasis on Soil-Transmitted Helminths (STH) among residents around Gilgel Gibe dam located in Jimma zone of Oromia regional state, Ethiopia.
\end{abstract}

Methods: A total of 1,021 participants were recruited in this study and provided stool samples for parasitological examination. Direct wet mount and Kato-Katz techniques were employed for stool examination. Pearson chi-square test was employed to assess the association of infection status and polyparasitism with gender and age group of the study participants.

Results: Five hundred thirty two individuals were infected with at least one parasite, providing the overall prevalence of 52.1\%. Among positive individuals, 405 (76.1\%), $114(21.4 \%)$, and 13 (2.5\%) individuals were infected with only one, two and three species of parasites, respectively. The overall prevalence of intestinal polyparasitism observed among the study participants was $12.4 \%(127 / 1,021)$. The predominant STH was hookworm, with a prevalence of $44.1 \%$. Hookworm and Ascaris lumbricoides were the most frequently recorded combination in cases of polyparasitic infection. The study revealed that there was no significant difference in the distribution of polyparasitism with regard to age group and sex of the study participants $(p>0.05)$.

Conclusion: The study indicated the presence of high prevalence of parasites as well as distribution of polyparasitism in the area. Moreover, the detection of Schistosoma mansoni in the community living within close proximity of the newly constructed dam would be taken as an indication of future risk factor. Further investigation on the predictors of polyparasitism and the assessment of effects of polyparasitism on the population are needed. Finally, there is a need to undertake integrated control strategies which involve improved sanitation, health education and chemotherapy that targets the whole community instead of only certain segments of populations.

Keywords: Polyparasitism, Soil-transmitted helminths, Prevalence, Gilgel Gibe, Jimma, Ethiopia

\footnotetext{
* Correspondence: zeleke.mekonnen@ju.edu.et

'Department of Medical Laboratory Sciences and Pathology, College of

Health sciences, Jimma University, Jimma, Ethiopia

Full list of author information is available at the end of the article
} 


\section{Background}

Intestinal parasitic infections (IPIs) remain one of the most public health problems where one third of the world population is generally estimated to be infected. The most affected people are children and the poor people living in tropics and subtropics, where there is poor personal hygiene and environmental sanitation, overcrowding, and limited access to clean water $[1,2]$. A concurrent infection with more than one parasitic species is also commonly observed among the same population [3].

The major IPIs affecting humans are the protozoan species (Entamoeba histolytica/dispar and Giardia lamblia) and helminthes (Ascaris lumbricoides, Trichuris trichiura, hookworms, Strongyloides stercolaris, Enterobius vermicularis) and other parasites (Hymenolepis nana, and Schistosoma mansoni). Among these IPIs, soil-transmitted helminthiasis and schistosomiasis are the most neglected tropical parasitic diseases disproportionately affecting the poor and most vulnerable populations with underprivileged living conditions. More than 1.5 billion people, $24 \%$ of the world population, are infected with soiltransmitted helminths (STHs) [4] causing 4.98 million years lived with disability [5]. As a result, about 300 million people suffer from severe morbidity attributed to STH infections, resulting in 10,000-135,000 deaths annually [6]. It is also estimated that 207 million people are infected with schistosomiasis worldwide, leaving 779 million people at risk of infection; the highest prevalence occurring in sub-Saharan Africa [7].

Although accurate estimate of the magnitude of polyparasitism (the concurrent infection with multiple intestinal parasite species) is unknown, the case is distributed widely in the tropics and sub-tropics [3]. As opposed to other pathogens, morbidity due to STH and schistosomiasis is related to the intensity of infection rather than the absence or presence of the parasites. It was found that individuals with polyparasitic infection also harbor the most intense infections $[8,9]$. Even low-intensity of polyparasitic infections may result in clinically significant morbidity $[10,11]$. Therefore, polyparasitism may have a greater impact on morbidity than single species infection. It may also increase susceptibility to other infections and adversely affect the clinical outcome of the concomitant diseases such as tuberculosis, HIV/AIDS and malaria [3, 12].

Even though the cases of polyparasitism are prevalent, few studies have considered its significance. Nevertheless, there is now increased emphasis on using a multispecies control approach as a cost-effective mechanism to control various helminth infections [9, 13]. In Ethiopia, IPIs are recognized as a major public health problem $[14,15]$. The burden and magnitude of IPIs in Ethiopia varies according to geographical location, climate and nature of soil, the segment of the population studied and other related socio-demographic and socio-economic factors [16-18].
The construction of hydroelectric dam in the area could be among the factors enhancing the transmission of schistosomiasis in a given area by facilitating the breeding sites for the intermediate host (snails). Given the already existing burden of STH, this might create the opportunity for polyparasitic infection with special emphasis on STHs and S. mansoni. Therefore, this study was designed to determine the prevalence and distribution of intestinal polyparasitism among residents around Gilgel Gibe Dam.

\section{Methods \\ Study area and setting}

The study was conducted in the Gilgel Gibe hydroelectric power dam catchment areas found at $10 \mathrm{~km}$ away from the periphery of the dam which are found in four districts (Omo Nada, Tiro Afata, Sekoru and Kersa) of Jimma zone in the Oromia national regional state to the south west part of Ethiopia. It included 13 Gotes/villages from a total of 7 rural Kebeles (the smallest administrative unit in the country) of the four districts. The study area comprised of 11,000 households with a total population of 50,000. The study area lies between latitudes $7^{0} 42^{\prime} 50^{\prime \prime} \mathrm{N}$ and $7^{0} 53^{\prime}$ $50^{\prime \prime} \mathrm{N}$, longitudes $37^{\circ} 11^{\prime} 22^{\prime \prime} \mathrm{E}$ and $37^{\circ} 20^{\prime} 36^{\prime \prime} \mathrm{E}$ at an altitude of 1672-1864 m above sea level. Gilgel Gibe dam is located at about $260 \mathrm{~km}$ south-west of Addis Ababa, the capital of Ethiopia; and $55 \mathrm{~km}$ north east of Jimma town. The dam started operating in 2004.

\section{Study design}

A cross-sectional community based parasitological survey was conducted among population living around the Gilgel Gibe dam catchment areas between November and December, 2009.

\section{Sample size and sampling techniques}

Sample size was calculated using single population proportion formula; assuming expected prevalence of $50 \%$, 95\% confidence level, $5 \%$ margin of error, $10 \%$ non response rate, and design effect of 3 . The sample size was finally calculated to be 1,190. A multi-stage cluster sampling technique was employed. Briefly, 13 villages were conveniently selected from the source population. The determined sample size was then proportionally allocated to the size of each of the 13 selected study villages. From each village households were randomly selected and all individuals within the selected households were included in the study.

\section{Parasitological methods}

All stool samples were collected between 9 and 10 am each morning and then transported to Jimma University parasitology laboratory. Sample processing and microscopic examination took place within $4 \mathrm{~h}$ of collection 
by direct wet mount, and on the portion of the stool sample Kato-Katz thick-smear techniques was prepared simultaneously and examined microscopically. Briefly, the Kato-Katz thick smears were prepared following standard operating procedures (SOPs) as described by WHO (1991) on microscope slides using a square template with a whole diameter of $6 \mathrm{~mm}$ and depth of $1.5 \mathrm{~mm}$, which is assumed to sample $41.7 \mathrm{mg}$ of stool. All slides were examined by experienced laboratory technologists within 30-60 min of preparation for the presence of STHs and other parasites and then after overnight for $S$. mansoni.

\section{Data analysis}

Data were coded, entered into, cleaned, and analyzed using SPSS for windows version 20.0. Frequencies were used for calculation of the prevalence of infection and polyparasitism. Pearson chi-square test was employed to identify any association of intestinal parasitic infection with gender and age group.

\section{Quality control}

Re-reading of $10 \%$ of the slides randomly selected was performed by senior microscopist blinded to the results for assuring the quality of results. Only three discrepancies were observed and after careful re-checking, the results of the senior microscopist were taken as final. The slides were examined within 30-60 min of preparation for not missing the hookworms.

\section{Results}

A total of 1021 individuals participated in the study and provided stool sample for parasitic examination, of which 518 (50.7\%) were males and 503 (49.3\%) were females. The age of the study participants ranged from 1 to 90 years, with the median age of 13 (Inter-quartile range: 6-27). Majority (40.7\%) of the study participants were in the age group of 6-19 years. Results of the study showed that 532 individuals were infected with at least one parasite, providing the overall prevalence of $52.1 \%$ among the studied communities. As indicated in Table 1, generally 10 different parasite species were identified in the present study. The predominant STHs infection was hookworm, with a prevalence of $44.1 \%$, followed by $A$. lumbricoides (10.3\%), and T. trichiura (4.4\%). The prevalence of the rest parasites are as follows: $H$. nana $(2.1 \%)$, Taenia spp (1.4\%), S. stercolaris (1.2\%), E. vermicularis (1.1\%), E. histolytica/dispar (0.7\%), S. mansoni (0.6\%) and G. lamblia (0.1\%) (Table 1).

Regarding infection intensity of STH and S. mansoni by Kato-Katz, the results revealed that all recorded infections were categorized as "light" except two A. lumbricoides cases which were "heavy". Table 1 shows that there was no significant difference in prevalence of intestinal parasites among male and female participants $(p=0.624)$. However, the infection rate significantly differed for the age groups of the study participants; individuals above 15 years of age were found to have higher prevalence of intestinal parasites (OR: 1.5, 95\% CI (1.1, 1.9). Specifically, the distribution of hookworm among the participants was significantly higher among individuals above 15 years of age $(p=0.001)$. Further analysis, as represented in Table 2 , revealed that infection with at least one parasitic species significantly differed among the age groups of female participants $(p=0.004)$ but there was no significant difference among the age groups of male participants $(p=0.089)$. Moreover, females in the reproductive age group had higher odds of infection with intestinal parasites than females under 15 years of age (OR: 1.7, 95\% CI $(1.2,2.4)$ ).

The overall prevalence of polyparasitism observed among the study participants was $12.4 \%$ (127/1021). Among individuals positive for any parasites, 405 (76.1\%), 114 (21.4\%), and $13(2.5 \%)$ were infected with one, two and three species of parasites, respectively. As indicated in Table 3, hookworm and A. lumbricoides were the most frequently recorded combination both as double infection (52 of 114) and triple infection with another parasite (frequency of 10 of 13). Furthermore, hookworm, $T$. trichiura, and $A$. lumbricoides were the predominant combination observed in triple infections (frequency of 5 of 13), followed by hookworm, $T$. trichiura and $H$. nana; and hookworm, T. trichiura and S. stercolaris (frequency of 2 of 13 for each).

Overall, 6 cases of intestinal schistosomiasis (S. mansoni) were reported in this study with a prevalence of $0.6 \%$. All of the schistosomiasis cases were found as part of polyparasitic infection. Out of 518 male participants, 66 (12.7\%) of them were found to have polyparasitism while $61(12.1 \%)$ of 503 female participants had polyparasitism. Similarly, out of 569 individuals $\leq 15$ years, $76(13.4 \%)$ of them were found to have polyparasitism, while $51(11.3 \%)$ of 452 individuals $>15$ years had polyparasitism. The distribution of polyparasitism among the study participants showed no significant difference with gender $(p=0.766)$ and across the age groups $(p=0.319)$ (Table 1$)$.

\section{Discussion}

The present study has attempted to assess the distribution of IPIs and polyparasitism among the study subjects. Although lower when compared to the previously reported prevalence of $83 \%$ from urban dwellers of Jimma zone [19], the current study reported still a high overall prevalence of IPIs (52.1\%). This difference might be attributed to time gap, because the previous study was conducted in 2004. Moreover, Jimma zonal health department successive reports since 2005 indicated much improvement in sanitation and personal hygiene 
Table 1 Age-sex distribution of the intestinal parasitic infection and polyparasitism among the study participants

\begin{tabular}{|c|c|c|c|c|c|c|c|c|c|c|c|c|}
\hline \multirow[t]{3}{*}{ Variables } & \multirow[t]{3}{*}{ Positives } & \multicolumn{11}{|c|}{ Frequency of infection with different species of parasites and polyparasitism } \\
\hline & & \multicolumn{5}{|l|}{ Nematodes } & \multicolumn{2}{|l|}{ Cestodes } & \multicolumn{2}{|c|}{ Protozoa } & \multirow{2}{*}{$\begin{array}{l}\text { Trematodes } \\
\text { SM }\end{array}$} & \multirow[t]{2}{*}{ PP } \\
\hline & & HW & $\mathrm{AL}$ & $\pi$ & SS & EV & TS & $\mathrm{HN}$ & EH & GL & & \\
\hline \multicolumn{13}{|l|}{ Gender } \\
\hline Male & 266 & 227 & 46 & 28 & 7 & 7 & 7 & 10 & 4 & 1 & 5 & 66 \\
\hline Female & 266 & 223 & 59 & 17 & 5 & 4 & 7 & 11 & 3 & 0 & 1 & 61 \\
\hline Total & $532(52.1 \%)$ & $450(44.1 \%)$ & $105(10.3 \%)$ & $45(4.4 \%)$ & $12(1.2 \%)$ & $11(1.1 \%)$ & $14(1.4 \%)$ & $21(2.1 \%)$ & $7(0.7 \%)$ & $1(0.1 \%)$ & $6(0.6 \%)$ & $127(12.4 \%)$ \\
\hline$p$-value & 0.624 & 0.869 & 0.134 & 0.115 & 0.596 & 0.823 & 0.956 & 0.773 & - & - & - & 0.766 \\
\hline \multicolumn{13}{|c|}{ Age groups (years) } \\
\hline$\leq 15$ & 271 & 224 & 65 & 30 & 6 & 10 & 5 & 14 & 5 & 1 & 2 & 76 \\
\hline$>15$ & 261 & 226 & 40 & 15 & 6 & 1 & 9 & 7 & 2 & 0 & 4 & 51 \\
\hline Total & $532(52.1 \%)$ & $450(44.1 \%)$ & 105 (10.3\%) & $45(4.4 \%)$ & $12(1.2 \%)$ & $11(1.1 \%)$ & $14(1.4 \%)$ & $21(2.1 \%)$ & $7(0.7 \%)$ & $1(0.1 \%)$ & $6(0.6)$ & $127(12.4 \%)$ \\
\hline$p$-value & 0.001 & 0.001 & 0.179 & 0.131 & 0.443 & 0.274 & 0.129 & 0.308 & - & - & - & 0.319 \\
\hline
\end{tabular}

Key: HW Hookworm, AL Ascaris lumbricoides, TT Trichuris trichiura, SS Strongyloides stercoralis, EV Enterobius vermicularis, TS Taenia spp, HN Hymenolepis nana, EH Entamoeba histolytica, GL Giardia lamblia, SM Schistosoma mansoni, PP Polyparasitism

through community mobilization and the extensive effort of health extension workers. Yet, the observed high prevalence of IPIs and polyparasitism indicates that communities of Gilgel Gibe dam area resides in heavily contaminated environment with parasites. It is also lower than the prevalence of $62.3 \%$ reported from Northwest Ethiopia [20], 72.9\% from Azezo [21], and 83.8\% from Southeast of Lake Langano [22]. However, it is higher than what was reported from elsewhere [2326]. These differences could be due to geographical and climatic variations, and as well might be due to sociodemographic and socio-economic differences of the study populations.

In this study, there was no significant difference in prevalence of any IPIs among the gender. This is similar to what was reported from elsewhere [25]. The predominant parasite infection found in this study was hookworm (44.1\%). This could be due to the fact that our study participants are from rural community and during study

Table 2 Association of sex and age group with Intestinal parasites infection status of the study subjects

\begin{tabular}{lllll}
\hline Sex and age group & No examined & Infected (\%) & OR (95\%Cl) & $p$-value \\
\hline Female & & & & \\
$\leq 15$ & 270 & $127(47.1)$ & 1 & 0.004 \\
$>15$ & 233 & $139(59.6)$ & $1.7(1.2,2.4)$ & \\
Total & 503 & $266(52.8)$ & & \\
Male & & & & 0.089 \\
$\leq 15$ & 299 & $144(48.2)$ & 1 & \\
$>15$ & 219 & $122(55.7)$ & $1.4(0.9,1.9)$ & \\
Total & 518 & $266(51.4)$ & & \\
\hline
\end{tabular}

period we observed that majority of the participants are working in the open farm for living; and this environment might favors the easy transmission of hookworm. This finding is consistent with the study conducted in rural Côte d'Ivoire, in which hookworm was the predominant STHs in the community with a prevalence of $45 \%$ [27]. In the present study, significant association was found between hookworm infection and age group. Older individuals were more infected with hookworm species than the younger population. It confirms the hypothesis that the probability of acquiring hookworm infection increases with age as the activity outside the household increases with age. This is consistent with the findings reported from elsewhere [25, 27].

Hookworm was predominantly found among individuals older than 15 years of age. This might have a negative implication for mass drug administration (MDA) which specifically focuses on school children (6-15 years of age) as majority of the infection is contributed by older individuals. Perhaps the MDA should include people older than 15 years of age for better control of the diseases. The low prevalence of S. stercolaris and E. vermicularis might be attributed to the employed technique used for screening and the heterogeneity of the study participants with respect to age. In the present study, specific techniques like scotch tape test and Harada Mori which are known to yield better results were not used as indicated in the limitation section.

The results of this study revealed that polyparasitism was prevalent among the study population with an overall prevalence of $12.4 \%$. These results are based on low sensitive diagnostic methods (direct wet mount and Kato-katz thick smear) and single stool sample examination. In addition to the limitation of those diagnostic methods, 
Table 3 Age-sex distribution of the parasites combination (polyparasitism) among the study participants

\begin{tabular}{|c|c|c|c|c|c|}
\hline \multirow{2}{*}{$\begin{array}{l}\text { Polyparasitism } \\
\text { type }\end{array}$} & \multirow[t]{2}{*}{ Frequency } & \multicolumn{2}{|c|}{ Gender } & \multicolumn{2}{|c|}{ Age group (years) } \\
\hline & & $\bar{M}$ & $\mathrm{~F}$ & $\leq 15$ & $>15$ \\
\hline \multicolumn{6}{|l|}{ Double infection } \\
\hline $\mathrm{HW}+\mathrm{AL}$ & 52 & 24 & 28 & 32 & 20 \\
\hline $\mathrm{HW}+\mathrm{TT}$ & 11 & 7 & 4 & 7 & 4 \\
\hline $\mathrm{AL}+\pi$ & 8 & 5 & 3 & 5 & 3 \\
\hline $\mathrm{HW}+\mathrm{EV}$ & 6 & 3 & 3 & 3 & 3 \\
\hline$H W+H N$ & 6 & 4 & 2 & 4 & 2 \\
\hline $\mathrm{HW}+\mathrm{SS}$ & 6 & 4 & 2 & 4 & 2 \\
\hline $\mathrm{HW}+\mathrm{TS}$ & 8 & 4 & 4 & 2 & 6 \\
\hline$H W+E H / D$ & 4 & 1 & 3 & 1 & 3 \\
\hline$A L+S M$ & 3 & 2 & 1 & 2 & 1 \\
\hline$H W+S M$ & 1 & 1 & - & - & 1 \\
\hline$\Pi+S M$ & 2 & 2 & - & 1 & 1 \\
\hline$\pi+S S$ & 2 & 1 & 1 & 2 & - \\
\hline$\Pi+\mathrm{HN}$ & 1 & - & 1 & 1 & - \\
\hline$T+E V$ & 1 & 1 & - & 1 & - \\
\hline $\mathrm{AL}+\mathrm{SS}$ & 1 & - & 1 & - & 1 \\
\hline$A L+E H / D$ & 1 & - & 1 & 1 & - \\
\hline$A L+E V$ & 1 & - & 1 & - & 1 \\
\hline \multicolumn{6}{|l|}{ Triple infection } \\
\hline $\mathrm{HW}+\mathrm{AL}+\pi \mathrm{T}$ & 5 & 2 & 3 & 4 & 1 \\
\hline $\mathrm{HW}+\mathrm{TT}+\mathrm{HN}$ & 2 & 1 & 1 & 2 & - \\
\hline $\mathrm{HW}+\mathrm{AL}+\mathrm{SS}$ & 2 & 1 & 1 & 2 & - \\
\hline $\mathrm{HW}+\mathrm{AL}+\mathrm{TS}$ & 1 & 1 & - & - & 1 \\
\hline $\mathrm{HW}+\mathrm{AL}+\mathrm{EV}$ & 1 & 1 & - & 1 & - \\
\hline $\mathrm{HW}+\mathrm{AL}+\mathrm{HN}$ & 1 & - & 1 & 1 & - \\
\hline $\mathrm{HW}+\mathrm{TT}+\mathrm{TS}$ & 1 & 1 & - & 1 & - \\
\hline
\end{tabular}

Key: HW Hookworm, AL A. lumbricoides, TT T. trichiura, EV E. vermicularis, TS Taenia species, HN H. nana, SS S. stercolaris, EH/D E. histolytica/dispar, SM S. mansoni

considering other confounding factors like day-to-day variation in eggs or cysts output of some of the parasites, the 'true prevalence' of polyparasitism is likely higher than what is reported. Moreover, our finding is in agreement with the finding of similar previous works [12, 19, 25, 28-30] where polyparasitism is commonly reported, although the reported prevalence varies considerably from place to place being either higher or lower than what we have reported here. In general, this variation could be attributed to different factors such as ecological and geographical location, climate and nature of soil, the segments of the populations studied, the diagnostic methods employed and other related socio-demographic and socio-economic factors.

The distribution of polyparasitism was not significantly associated with gender. This was similar with the finding of a study published elsewhere [24]. The most frequently encountered parasites combination, in cases of polyparasitism, was the concurrent infection with hookworm and A. lumbricoides, which accounted for $48.8 \%$ (62/127) coexisting as (double and triple infection) among the study participants (Table 3). This is consistent with other studies conducted elsewhere [26, 31]. This might be due to the residential area of the communities studied where outdoor activity is common and similarity of the two parasites in contaminating the soil or environment that could serve as source of infection. Similarly, we observed significant association between A. lumbricoides and T. trichiura in the present study which is in agreement with other studies [27, 32, 33] making possible the contribution of oro-fecal route transmission of both parasites. In general as indicated in Table 3, our study has shown the co-infection of the different parasites in the studied communities particularly indicating the overlap of different STHs among themselves and with other IPIs indicating that the communities are at risk of acquiring multiple-parasites infections and calling for integrated control approaches.

Furthermore, this finding also reported $0.6 \%$ of $S$. mansoni. Given that there was no evidence of schistosomiasis case report around Gilgel Gibe dam community coupled with the newly formed body of water due to the hydroelectric dam, the authors believe that this finding highlights the potential risk of schistosomiasis as a threat to that particular community in the near future, even if the prevalence appears very low for now. Thus, regular survey for schistosomiasis as well as close follow-up for malocological evidence is indicated to prevent the possibility of potential raise of schistosomiasis cases.

\section{Conclusion}

Our study highlighted the prevalence of intestinal polyparasitism among residents around Gilgel Gibe dam. Hookworm infection was the predominant STHs in the area. Age group was significantly associated with infection. The distribution of hookworm was significantly high among people older than 15 years of age. This might hamper the outcome of MDA, which focuses on school children, suggesting the need to include individuals other than school children. The most frequent combination of parasites in polyparasitized individuals was hookworm and A. lumbricoides. Further study is needed to investigate risk factors and predictors of polyparasitism with STHs in the study area. A study designed to investigate the effect of polyparasitism on individuals should be in place as well. Integrated control strategies which consider, community health education, personal hygiene and improved sanitation including MDA that targets the whole community instead of only certain segments of populations need to be considered for effective control of IPIs. 


\section{Strength and limitation of the study}

In contrast to many studies focusing on narrow age group, this study focused on the entire population having an age range of 1 to 90 years and used large sample size. However, due to logistic reasons, the study did not consider all possible available stool sample examination techniques to exhaustively determine all intestinal parasites with maximum sensitivity and was limited to use of only single stool sample. Therefore, the reported results in this study might be much less than the 'true prevalence' among the studied communities. Additionally, although we did reading of kato-katz smears within $30 \mathrm{~min}$ for maximum recovery of hookworms, we did not carry further examination to identify hookworm species.

\section{Acknowledgements}

The authors are grateful to community leaders and study participants. Additionally, we would like to thank the staff of Medical Laboratory Sciences, Jimma University, including Mio Ayana, Dereje Jirata and Dereje Atomisa for processing and examining the stool samples.

\section{Funding}

This research work was funded by Jimma University.

\section{Availability of data and materials}

All data generated or analysed during this study are included in this manuscript, except few sensitive information like name (s) of the study participants linked to their stool results.

\section{Authors' contributions}

Conceiving and designing the study: ZM. Conducting the survey: ZM, SS, AB, $\Pi T$ and $\mathrm{LCH}$. Analyzing and interpreting the data: $Z M$ and $\Pi$. Drafting the manuscript; $T$ and $Z M$ and Reviewing the manuscript: SS; ZM; LCH and $A B$. Finally all the authors read and approved the manuscript.

\section{Competing interests}

The authors declare that they have no competing interests.

\section{Consent for publication}

Not applicable.

\section{Ethics approval and consent to participate}

Ethical clearance was obtained from Jimma university ethical review board. Written informed consent was obtained from each study participants after the objective of the study was explained. For individuals found infected with STHs and S. mansoni appropriate treatment (i,e., a single oral dose of $400 \mathrm{mg}$ Albendazole and $40 \mathrm{mg} / \mathrm{kg}$ of Praziquantel were provided for free by health professional of the research team, respectively. Others, who were infected by other parasites than STH and S. mansoni, were referred to the nearby health center for appropriate treatment.

\section{Author details}

'Department of Medical Laboratory Sciences and Pathology, College of Health sciences, Jimma University, Jimma, Ethiopia. ${ }^{2}$ Department of Pharmacy, College of Health Sciences, Jimma University, Jimma, Ethiopia.

Received: 23 January 2016 Accepted: 18 November 2016 Published online: 23 November 2016

\section{References}

1. de Silva NR, Brooker S, Hotez PJ, Montresor A, Engels D, Savioli L. Soiltransmitted helminth infections: updating the global picture. Trends Parasitol. 2003;19(12):547-51.

2. Prajapati BK, Rajput AH, Shah AD, Kadam MT. Case report: A case of Polyparasitism in a 10 year old child. Indian J Basic Appl Med Res. 2012;1(3):239-41.
3. Pullan R, Brooker S. The health impact of polyparasitism in humans: are we under-estimating the burden of parasitic diseases? Parasitol. 2008;135(7):783-94.

4. WHO. Soil transmitted helminths. Fact sheet no. 366 updated April 2014 available at: http//www.who.int/mediacentre/factsheets/fs366/en/. Accessed 20 Feb 2014

5. Pullan RL, Smith $J$, Jasrasaria R, Brooker SJ. Global numbers of infection and disease burden of soil transmitted helminth infections in 2010. Parasit Vectors. 2014;7:37

6. WHO. Research priorities for helminth infections: technical report of the TDR disease reference group on helminth infections, Technical report series; no. 972. Geneva: WHO; 2012

7. Hotez PJ, Molyneux DH, Fenwick A, Kumaresan J, Sachs SE, Sachs JD, Savioli L. Control of Neglected Tropical Diseases. N Engl J Med. 2007;357:1018-27.

8. Brooker S, Miguel EA, Moulin S, Luoba Al, Bundy DA, Kremer M. Epidemiology of single and multiple species of helminth infections among school children in Busia District, Kenya. East Afr Med J. 2000;77:157-61.

9. Tchuem Tchuente LA, Behnke JM, Gilbert FS, Southgate VR, Vercruysse J. Polyparasitism with Schistosoma haematobium and soil-transmitted helminth infections among school children in Loum, Cameroon. Trop Med Int Health. 2003;8:975-86.

10. Ezeamama AE, Friedman JF, Olveda RM, Acosta LP, Kurtis JD, Mor V, McGarvey ST. Functional significance of low-intensity polyparasite helminth infections in anemia. J Infect Dis. 2005;192:2160-70.

11. Sorensen WC, Cappello M, Bell D, DiFedele LM, Brown MA. Poly-helminth infection in east guatemalan school children. J Global Infect Dis. 2011;3:25-31.

12. Onah IE, Omudu EA, Emmy-Egbe IO, Ekwesianya EO, Ukaga CN, Ajero CMU, et al. Prevalence of polyparasitism in kwasa village (a sub-urban settlement) in makurdi, Benue state, Nigeria. Global Res J Sci. 2011;1:98-103.

13. Drake $\amalg$, Bundy DA. Multiple helminth infections in children: impact and control. Parasitol. 2001;122(I):73-81.

14. Degarege A, Legesse M, Girmay M, Animut A, Erko B. Malaria andrelated outcomes in patients with intestinal helminths: a cross sectional study. BMC Infect Dis. 2012. doi:10.1186/1471-2334-12-291.

15. Cheesbrough M. District laboratory practices in tropical countries. Part I. England: Cambridge University Press; 2005. p. 220-1.

16. Nyantekyi L, Legesse M, Medhin G, Animut A, Tadesse K, Macias C, Degarege A, Erko B. Community awareness of intestinal parasites and the prevalence of infection among community members of rural Abaye Deneba area, Ethiopia. Asian Pac J Trop Biomed. 2014;4 Suppl 1:S152-7.

17. Deribe K, Meribo K, Gebre T, et al. The burden of neglected tropical diseases in Ethiopia, and opportunities for integrated control and elimination. Parasit Vectors. 2012;5:article 240.

18. Jejaw A, Zeynudin A, Zemene E, Belay T. Status of intestinal parasitic infections among residents of Jimma Town, Ethiopia. BMC Res Notes. 2014;7:502.

19. Mengistu A, Gebre-Selassie S, Kassa T. Prevalence of intestinal parasitic infections among urban dwellers in southwest Ethiopia. Ethiop J Health Dev. 2007:21(1):12-7.

20. Abate A, Kibret B, Bekalu E, Abera S, Teklu T, Yalew A, et al. Cross-Sectional Study on the Prevalence of Intestinal Parasites and Associated Risk Factors in Teda Health Centre, Northwest Ethiopia. ISRN Parasitology. 2013:Article ID 757451.

21. Endris M, Lemma W, Belyhun Y, Moges B, Gelaw A, Angaw B. Prevalence of intestinal parasites and associated risk factors among students of Atse Fasil general elementary school Azezo, Northwestern Ethiopia. Ethiopian J Health Biomed Sci. 2010;1(3):25-33.

22. Legesse M, Erko B. Prevalence of intestinal parasites among school children in rural area close to the south east of Lake Langano, Ethiopia. Ethiop J Health Dev. 2004;18(2):116-20.

23. Wegayehu T, Tsalla T, Seifu B, Teklu T. Prevalence of intestinal parasitic infections among highland and lowland dwellers in Gamo area, South Ethiopia. BMC Public Health. 2013;13:151.

24. Gelaw A, Anagaw B, Nigussie B, Silesh B, Yirga A, Alem M, et al. Prevalence of intestinal parasitic infections and risk factors among schoolchildren at the University of Gondar Community School Northwest Ethiopia: a crosssectional study. BMC Public Health. 2013;13:304.

25. Kounnavong S, Vonglokham M, Houambouna K, Odermatt P, Boupha B. Soil-transmitted helminth infections and risk factors in preschool children in southern rural Lao People's Democratic Republic. Trans R Soc Trop Med Hyg. 2011;105:160-6.

26. Belizario Jr VY, Totanes FG, de Leon WU, Lumampao YF, Ciroa RT. Soiltransmitted helminth and other intestinal parasitic infections among school children in indigenous people communities in Davao del Norte, Philippines. Acta Trop. 2011;120 suppl 1:S12-8. 
27. Raso G, Luginbüh A, Adjoua CA, Tian-Bi NT, Silué KD, Matthys B, et al. Multiple parasite infections and their relationship to self-reported morbidity in a community of rural Côte d'Ivoire. Int J Epidemiol. 2004;33:1092-102.

28. Midzi N, Sangweme D, Mtapuri-Zinyower S, Mapingure MP, Brouwer KC, Munatsi A, et al. The burden of polyparasitism among primary schoolchildren in rural and farming areas in Zimbabwe. Trans R Soc Trop Med Hyg. 2008;102:1039-45.

29. Midzi N, Mtapuri-Zinyower S, Mapingure MP, Sangweme D, Chirehwa MT, Brouwer KC, Mudzori J, Hlerema G, Mutapi F, Kumar N, Mduluza T. Consequences of polyparasitism on anaemia among primary schoo children in Zimbabwe. Acta Trop. 2010;115:103-11.

30. Okyay P, Ertug S, Gultekin B, Onen O, Beser E. Intestinal parasites prevalence and related factors in school children, a western city sample-Turkey. BMC Public Health. 2004;4:64.

31. Petney TN, Andrews RH. Multiparasite communities in animals and humans: frequency, structure and pathogenic significance. Int J Parasitol. 1998;28:377-93.

32. Howard SC, Donnelly CA, Chan MS. Methods for estimation of associations between multiple species parasite infections. Parasitol. 2001;122:233-51.

33. Booth M, Bundy DAP. Comparative prevalences of Ascaris lumbricoides, Trichuris trichiura and hookworm infections and the prospects for combined control. Parasitol. 1992;105:151-57.

\section{Submit your next manuscript to BioMed Central and we will help you at every step:}

- We accept pre-submission inquiries

- Our selector tool helps you to find the most relevant journal

- We provide round the clock customer support

- Convenient online submission

- Thorough peer review

- Inclusion in PubMed and all major indexing services

- Maximum visibility for your research

Submit your manuscript at www.biomedcentral.com/submit 